\title{
Behçet Hastalarının Uyku Kalitesi, Depresyon Düzeyi ve Etkileyen Faktörler
}

\section{Can ARAZ ${ }^{1}$, Altuğ GÜNER ${ }^{2}$, Seda PEHLIVAN ${ }^{3}$, Yavuz PEHLIVAN ${ }^{2}$}

$1 \quad$ Akdeniz Üniversitesi Tıp Fakültesi, Antalya.

2 Bursa Uludağ Üniversitesi Tıp Fakültesi, Romatoloji Bilim Dalı, Bursa.

3 Bursa Uludağ Üniversitesi Sağlık Bilimleri Fakültesi, Hemşirelik Bölümü, İç Hastalıkları Hemşireliği Anabilim Dalı, Bursa.

\section{ÖZET}

Calıșma, Behçet hastalarının uyku kalitesi, depresyon düzeyleri ve etkileyen faktörleri belirlemek amacıyla tanımlayıcı olarak yapıldı. Calışmaya katılmayı kabul eden 44 Behçet hastası çalışmaya dahil edildi. Çalışmanın verileri, araştırmacılar tarafından hazırlanan "Hasta Bilgi Formu", "Pitsburg Uyku Kalitesi İndeksi (PUKİ)", "Beck Depresyon Ölçeği (BDÖ)", Behçet Hastalı̆̆ı Yașam Kalitesi Ölçeği (BHYKÖ)" ve "Behçet Hastalığı Güncel Aktivite Formu" ile toplandı. Verilerin değerlendirilmesinde, Mann Whitney U ve Spearman korelasyon analizleri yapıldı. Hastaların yaş ortalamasının 37,38 $\pm 8,33$ yıl, \%90,9'unun erkek ve hastalık süresi ortalamasının 7,54 $\pm 4,72$ yıl olduğu belirlendi. Genital ülseri olan hastaların PUKİ puanının anlamlı olarak yüksek olduğu saptandı ( $<0,05)$. Diğer tanımlayıcı özellikler açısından PUKİ, BDÖ, BHYKÖ puanları arasında anlamlı bir fark bulunmadı $(\mathrm{p}>0,05)$. Hastalık aktivite skoru ile PUKİ, BDÖ, BHYKÖ puanları arasında anlamlı ilişki olduğu belirlendi $(p<0,05)$. Ayrıca üç ölçek arasında da anlamlı pozitif korelasyon olduğu görüldü $(p<0,05)$. Behçet hastalarında hastalık aktivitesinin uyku kalitesi, depresyon düzeyi ve yaşam kalitesi açısından önemli bir belirleyici olduğu sonucuna varıldı. Hastalık aktivitesi kontrol altında tutularak Behçet hastalarının uyku kalitesi, depresyon düzeyi ve yaşam kalitesinin iyileştirilebileceği düşünülmektedir.

Anahtar Kelimeler: Behçet hastalı̆̆ı. Depresyon. Uyku kalitesi. Yaşam kalitesi.

Sleep Quality, Depression Level and Affecting Factors of Behçet's Patients

\begin{abstract}
The study was carried out descriptively to determine the quality of sleep, depression levels and factors affecting Behçet patients. 44 Behçet patients who agreed to participate in the study were included in the study. The data of the study were collected with the "Patient Information Form" prepared by the researchers, "Pitsburg Sleep Quality Index", "Beck Depression Scale Behçet's Disease Quality of Life Scale" and "Behçet's Disease Current Activity Form". In the evaluation of the data, Mann Whitney U and Spearman correlation analyzes were performed. It was determined that the mean age of the patients was $37.38 \pm 8.33$ years, $90.9 \%$ of them were male and the mean duration of the disease was $7.54 \pm 4.72$ years. It was found that patients with genital ulcers had a significantly higher PSQI score (p \&lt;0.05). In terms of other descriptive features, there was no significant difference between PSQI, BDI, BDIQ scores (p\&gt; 0.05). It was determined that there was a significant relationship between the disease activity score and PSQI, BDI, SCQQ scores (p \&lt;0.05). In addition, there was a significant positive correlation between the three scales ( $p$ \&lt;0.05). It was concluded that disease activity was an important determinant in Behçet's patients in terms of sleep quality, depression level and quality of life. It is thought that the quality of sleep, depression level and quality of life of Behçet patients can be improved by keeping disease activity under control.
\end{abstract}

KeyWords: Behçet's disease. Depression. Sleep quality. Quality of life.

Geliş Tarihi: 11.Mart.2020

Kabul Tarihi: 10.Haziran.2020

Dr. Altuğ GÜNER

Bursa Uludağ Üniversitesi Tıp Fakültesi,

Romatoloji Bilim Dalı,

Bursa.

Tel.: 05452482266

E-posta: guner_88_8@hotmail.com

Yazarların ORCID ID Bilgisi:

Altuğ GÜNER: 0000-0001-7220-0288

Can ARAZ: 0000-0002-5014-6943

Seda PEHLIVAN: 0000-0002-1670-0672

Yavuz PEHLIVAN: 0000-0002-7054-5351
1937 y1lında ilk kez Hulusi Behçet tarafindan ortaya konan Behçet hastalığı $(\mathrm{BH})$ başlangıçta tekrarlayan oral ülserler, genital ülserler ve hipopiyonlu üveit ile karakterize üçlü semptom kompleksi olarak tanımlanmıştır'. Günümüzde ise BH'nın bu üç belirtiye ek birçok bulguya sebep olduğu dermatolojik, vasküler, nörolojik, lökomotor, intestinal, ürogenital ve kardiyopulmoner semptomların eşlik edebildiği multisistemik kronik inflamatuar bir hastalık olduğu bilinmektedir ${ }^{1-8}$. 
Mikroorganizmaların da yer aldığı çevresel faktörler genetik yatkınlığı olan bireylerde humoral ve hücresel immünitede bozukluklar meydana getirmektedir. $\mathrm{Bu}$ etkilenim sonrası ortaya çıan inflamasyon BH'nin etyopatogenizinden sorumlu tutulmaktadir ${ }^{9-12}$. $\mathrm{Bu}$ inflamasyonun ortaya çıkısında stresörlerin de etkili olduğu gösterilmiştir. Literatürde $\mathrm{BH}$ 'li hastaların çoğunda hastalık başlangıç ve relapslarında etkili olan stres faktörlerinin varlığı bildirilmiş olması rağmen $\mathrm{BH}$ etyolojisi tam olarak aydınlatılamamıştır ${ }^{13,14}$.

Multisistemik kronik inflamatuar bir hastalık olan BH tanılı olgularda en sik depresyon ve anksiyete olmakla beraber psikiyatrik belirtiler görülmektedir. Bu psikiyatrik belirtilerin etyopatogenizi tam olarak ortaya konmamasına rağmen hastalık izleminde görülen progresyon ve fonksiyonel bozukluklar ile tedavide kullanılan kortikosteroidlerin belirtilerle ilişkili olabileceği ileri sürülmektedir. Ayrıca BH'nın belirtiler üzerinde etkili olduğu kadar görülen anksiyete, depresyon ile yüksek stresli yaşam koşullarınında $\mathrm{BH}$ tanılı olgularda etkili olduğu özellikle hastalığın ortaya çıkışına ve nükslere sebep olabileceği ortaya konmuştur. $\mathrm{Bu}$ sebeple psikiyatrik belirtilerin BH'nin sebebi mi sonucu mu olduğu çatışma konusudur ${ }^{15,16}$.

$\mathrm{BH}$ ile birlikte görülen psikiyatrik bozukluklar ve diğer organ yetmezlikleri hastalık yaşam kalitesi ve uyku kalitesinde bozulmalara sebep olabilmektedir. Bundan dolayı son yıllarda kronik hastalıkların zihinsel koşullarını, uyku kalitesi ve yaşam kalitesini araştıran çalışmalar artmıştır ${ }^{17}$. Literatürde de $\mathrm{BH}$ olgularında depresyon varlığının ortaya konduğu, yaşam kalitesi ve uyku kalitesinin olumsuz yönde etkilendiği birçok çalışma karşımıza çıkmaktadır ${ }^{18-22}$. Bizde çalışmamızda $\mathrm{BH}$ tanısı konmuş kişilerin uyku düzenleri, yaşam kaliteleri ve depresyon durumlarının incelenmesini, bu belirteçlerin hastalık aktivasyonu ile ilişkisini araştırmayı amaçladık.

\section{Gereç ve Yöntem}

Tanımlayıcı nitelikte olan çalışma, 13/05/2019 tarihinden itibaren üç aylık sürede bir üniversite hastanesinin romatoloji polikliniğinde takip edilen Behçet hastaları ile yapıldı. Çalışmaya, araştırmanın uygulama süresi içinde ulaşılabilen ve çalışmaya katılmayı kabul eden toplam 44 hasta alındı. Çalışmaya katılmay1 kabul etmeyen, hastanede yatarak tedavi edilen, ek hastalığı olan ve anketin tamamını doldurmayan hastalar çalışma dışında bırakıldı. Çalışmanın etik kurul izni Uludağ Üniversitesi Tıp Fakültesi Klinik Araştırmalar Etik Kurulu'ndan alındı (Tarih: 07.05.2019 ve Karar No:2019-8/42). Ayrıca çalışmaya alınan hastalardan bilgilendirilmiş onam alındı.

\section{Veri Toplama Araçları}

Araştırmanın verilerinin toplanmasında, "Hasta Bilgi Formu", "Pitsburg Uyku Kalitesi İndeksi", "Beck
Depresyon Ölçeği”, "Behçet Hastalığı Yaşam Kalitesi Ölçeğii" ve "Behçet Hastalığı Güncel Aktivite Formu" kullanıld1.

Hasta Bilgi Formu: yaş, cinsiyet, hastalık başlangıç yaşı, BH'i bulgularının varlığı açısından değerlendirme sorularının yer aldığ formdur.

Pitsburg Uyku Kalitesi İndeksi (PUKİ): Buyse ve arkadaşları (1989) tarafindan geliştirilen ölçeğin, Türkçe geçerlik ve güvenirlik çalışması Ağargün ve arkadaşları (1996) tarafindan yapılmıştır ${ }^{23,24}$. Cronbach alfa iç tutarlılık katsayısı 0.80 olarak saptanmıştır. Uyku kalitesini değerlendirmek amaciyla kullanılan ölçekte son 4 haftadaki uyku kalitesini sorgulayan 24 soru yer almaktadır. Ölçeğin 7 bileşeni bulunmakla birlikte, her bir bileşen 0-3 puan arasında değerlendirilmektedir. Toplam PUKİ puanı 0-21 arasında değişmekte olup, 5 'ten yüksek puan kötü uyku kalitesini göstermektedir ${ }^{25}$.

Beck Depresyon Ölçeği (BDÖ): Depresyon riskini ve depresif belirtilerin düzeyini belirlemek amacıyla Beck tarafindan geliştirilen ölçek, 4'lü likert tipinde bir özbildirim ölçeğidir ${ }^{26}$. Türkçe geçerlik ve güvenilirliği Hisli (1989) tarafindan yapılan ölçeğin Cronbach alfa katsayısı 0.80 olarak bulunmuştur. Toplam 21 maddeden oluşan ölçekte, her madde için " $0=$ Depresyonla İlgili Olumlu İfadeler" ve "3=Depresyonla İlgili Olumsuz İfadeler” olacak şekilde değerlendirme yapılmaktadır. Ölçekten alınabilecek puan 0 ile 63 arasında değişmektedir. Ölçeğin Türkçe geçerlik ve güvenirlik çalışmasında kesme puanı 17 kabul edilmiştir ${ }^{27}$.

Behçet Hastalı̆̆ı Yaşam Kalitesi Ölçeği (BHYKÖ): Behçet hastalarının son bir ay içindeki yaşam kalitesini ölçmek amacıyla Gilworth ve arkadaşları (2004) tarafından geliştirilmiştir ${ }^{28}$. Erdoğan ve Pınar (2009) tarafından yapılan Türkçe geçerlik ve güvenirlik çalışmasında, ölçeğin güvenirlik katsayısının 0,95 olduğu belirlenmiştir ${ }^{29}$. Ölçek, "doğru” ve "yanlış" yanıt seçenekleri bulunan 30 ifadeden oluşmaktadır. Değerlendirmede her "doğru" yanıtına 1 puan verilerek toplam puan hesaplanır. Toplam puanın 0-30 arasında değiştiği ölçekte; 0 en iyi, 30 en kötü yaşam kalitesini ifade etmektedir ${ }^{30}$.

Behçet Hastalığı Güncel Aktivite Formu: Bhakta ve arkadaşları tarafindan oluşturulan ölçeğin ${ }^{31}$, Türkçe geçerlik ve güvenilirliği çalışması Hamuryudan ve arkadaşları tarafindan yapılmıştır ${ }^{32}$. Baş ağrısı, oral ülserler, genital ülserler, cilt lezyonları, eklem tutulumu, gastrointestinal semptomlar, göz tutulumu, sinir sistemi tutulumu ve majör damar tutulumu olmak üzere sık gözlenen belirtiler sorgulanmaktadır. 7 farklı yüz ifadesi içeren görsel Likert çizelgesi işaretlenir. Puan yüksekliği hastalık aktivitesinin daha fazla olduğunu göstermektedir. Ölçekte 5 puanın üstü hastalık aktivitesinin "yüksek" olduğuna işaret etmektedir.

Anketler, katılımcılar ile yüz yüze görüşme yöntemi ile yaklaşık 20-25 dakikada dolduruldu. 


\section{Behçet Hastalarının Uyku Kalitesi}

\section{Verilerin Değerlendirilmesi}

İstatistiksel analizlerde SPSS 20,0 programı kullanıld1. Shapiro-Wilk testi ile normallik analizi yapıldı. Veriler normal dağılım göstermediğinden analizlerde nonparametrik testler kullanıldı. Sürekli değişkenlerin, iki grup karşılaştırmasında Mann Whitney U ve değişkenler arasındaki ilişkinin incelenmesinde Spearman korelasyon analizlerinden yararlanıldı. İstatistiksel anlamlılık değeri $\mathrm{p}<0,05$ olarak kabul edildi.

\section{Bulgular}

Hastaların sosyodemografik ve hastalık özellikleri ile PUKİ ve Beck Depresyon ölçeği puan ortalamaları arasındaki ilişki Tablo I ve II'de görülmektedir.

Tablo I. Behçet hastalarının PUKİ, BDÖ, BHYKÖ puanlarının sosyodemografik ve hastalık özelliklerine göre dağılımı

\begin{tabular}{|c|c|c|c|c|}
\hline Özellikler & $\mathrm{n}(\%)$ & $\begin{array}{c}\text { PUKI } \\
\text { Med (Min- } \\
\text { Max) }\end{array}$ & $\begin{array}{c}\text { BDÖ } \\
\text { Med (Min- } \\
\text { Max) }\end{array}$ & $\begin{array}{c}\text { BHYKÖ } \\
\text { Med (Min- } \\
\text { Max) }\end{array}$ \\
\hline \multicolumn{5}{|l|}{ Cinsiyet } \\
\hline Kadın & $4(9,1)$ & $6,5(0-17)$ & $31,5(9-35)$ & $20(5-24)$ \\
\hline Erkek & $44(90,9)$ & $10(2-16)$ & $14,5(0-44)$ & $10,5(0-30)$ \\
\hline p değeri & & 0,490 & 0,256 & 0,373 \\
\hline \multicolumn{5}{|l|}{ Oral aft } \\
\hline Var & $36(81,8)$ & $7(0-17)$ & $15,5(0-44)$ & $13(0-30)$ \\
\hline Yok & $8(18,2)$ & $4(0-14)$ & $11(6-35)$ & $7,5(0-25)$ \\
\hline$p$ değeri & & 0,119 & 0,272 & 0,300 \\
\hline \multicolumn{5}{|l|}{ Genital ülser } \\
\hline Var & $25(56,8)$ & $7(0-17)$ & $19(0-44)$ & $14(0-30)$ \\
\hline $\begin{array}{l}\text { Yok } \\
\quad p \text { değeri }\end{array}$ & $19(43,2)$ & $\begin{array}{c}5(0-10) \\
0,027\end{array}$ & $\begin{array}{c}14(0-42) \\
0,265\end{array}$ & $\begin{array}{c}9(0-30) \\
0,296\end{array}$ \\
\hline \multicolumn{5}{|l|}{ Cilt tutulumu } \\
\hline Var & $36(81,8)$ & $6(0-17)$ & $15(0-44)$ & $11,5(0-30)$ \\
\hline Yok & $8(18,2)$ & $7(2-14)$ & $13,5(0-44)$ & $12(0-26)$ \\
\hline \multicolumn{4}{|l|}{ Göz tutulumu } & 0,560 \\
\hline Var & $20(45,5)$ & $7(0-17)$ & $15,5(0-44)$ & $14(0-30)$ \\
\hline Yok & $24(54,5)$ & $6(2-16)$ & $13,5(0-43)$ & $9,5(0-28)$ \\
\hline p değeri & & 0,227 & 0,248 & 0,310 \\
\hline \multicolumn{5}{|l|}{ Eklem tutulumu } \\
\hline Var & $18(40,9)$ & $6(2-14)$ & $14,5(2-44)$ & $14(0-30)$ \\
\hline Yok & $26(59,1)$ & $7(0-17)$ & $15(0-44)$ & $9,5(0-30)$ \\
\hline p değeri & & 0,429 & 0,943 & 0,693 \\
\hline \multicolumn{5}{|l|}{ Nörolojik tutulum } \\
\hline Var & $12(27,3)$ & $7(0-17)$ & $22,5(0-44)$ & $11(0-30)$ \\
\hline Yok & $32(72,7)$ & $6(0-16)$ & $14,5(0-44)$ & $11,5(0-30)$ \\
\hline p değeri & & 0,340 & 0,589 & 0,958 \\
\hline \multicolumn{5}{|l|}{ Gis tutulumu } \\
\hline Var & $4(9,1)$ & $8,5(6-14)$ & $32,5(4-36)$ & $24(4-29)$ \\
\hline Yok & $40(90,9)$ & $6,5(0-17)$ & $14,5(0-44)$ & $10,5(0-30)$ \\
\hline p değeri & & 0,251 & 0,288 & 0,152 \\
\hline \multicolumn{5}{|l|}{ Vasküler tutulum } \\
\hline Var & $20(45,2)$ & $5(0-13)$ & $13(0-44)$ & $9(0-29)$ \\
\hline Yok & $24(55,5)$ & $7(0-17)$ & $16(0-44)$ & $14(0-30)$ \\
\hline$p$ değeri & & 0,140 & 0,619 & 0,448 \\
\hline \multicolumn{5}{|l|}{ HLA B51 pozitifliği } \\
\hline Var & $28(63,6)$ & $6(0-17)$ & $15,5(0-44)$ & $11,5(0-30)$ \\
\hline Yok & $16(36,4)$ & $7(2-14)$ & $13,5(2-44)$ & $12(0-30)$ \\
\hline p değeri & & 0,902 & 0,951 & 0,769 \\
\hline \multicolumn{5}{|l|}{ Paterji Testi pozitifliği } \\
\hline Var & $21(47,7)$ & $7(0-17)$ & $16(2-35)$ & $12(0-30)$ \\
\hline Yok & $23(52,3)$ & $6(0-14)$ & $14(0-44)$ & $9(0-30)$ \\
\hline p değeri & & 0,327 & 0,869 & 0,698 \\
\hline Toplam & $44(100,0)$ & $6,5(0-17)$ & $15(0-44)$ & $11,5(0-30)$ \\
\hline
\end{tabular}

Tablo II. Behçet hastalarının yaş, hastalık süresi, hastalık aktivite skoru ile PUKİ, BDÖ, BHYKÖ puanlarının korelasyonu

\begin{tabular}{|lcccccc|}
\hline & \multicolumn{2}{c}{ PUKi } & \multicolumn{2}{c}{ BDÖ } & \multicolumn{2}{c|}{ BHYKÖ } \\
& $\mathbf{r}$ & $\mathbf{p}$ & $\mathbf{r}$ & $\mathbf{p}$ & $\mathbf{r}$ & $\mathbf{p}$ \\
\hline Yaş & $-0,089$ & 0,565 & 0,130 & 0,401 & 0,087 & 0,572 \\
Hastalık süresi & $-0,066$ & 0,670 & $-0,093$ & 0,547 & 0,097 & 0,530 \\
BAS & $\mathbf{0 , 4 4 5}$ & $\mathbf{0 , 0 0 2}$ & $\mathbf{0 , 6 2 0}$ & $<0,001$ & $\mathbf{0 , 6 0 0}$ & $<0,001$ \\
PUKi & - & - & $\mathbf{0 , 6 1 8}$ & $<0,001$ & $\mathbf{0 , 6 0 8}$ & $<0,001$ \\
BECK & & & - & - & $\mathbf{0 , 8 5 9}$ & $<0,001$ \\
\hline
\end{tabular}

Behçet hastalarının yaş ortalaması $37,38 \pm 8,33$ yıl ve \%90,9'unun erkek olduğu saptand1. Hastalık süresi ortalamasının 7,54 $\pm 4,72$ y1l, $\% 81,8$ 'inde oral ülser ve $\% 56,8$ 'inde genital ülser olduğu belirlendi. Sistem ve organ tutulumu dağılımına bakıldığında; \%81,8 cilt, \%45,5 göz, \%40,9 eklem, \%27,3 nörolojik, \%9,1 gastrointestinal, \%45,2 vasküler tutulum olduğu saptandi.

PUKİ puanı ortanca değerinin 6,5 (0-17) olduğu ve Behçet hastalarının kötü uyku kalitesine sahip olduğu belirlendi. BDÖ puanı ortanca değerinin 15 (0-44) olduğu ve depresyon puanının düşük olduğu saptandı. BHYKÖ puanı ortanca değeri 11,5 (0-30) bulundu ve yaşam kalitesinin iyi olduğu belirlendi. Araştırmada incelenen parametrelerden sadece genital ülseri olan hastaların PUKİ puanının anlamlı olarak yüksek olduğu saptandı $(p<0,05)$. Diğer tanımlayıcı özellikler açısından PUKİ, BDÖ, BHYKÖ puanları arasında anlamlı bir fark bulunmadı $(\mathrm{p}>0,05)$. Hastalık aktivite skoru 3,15 2,59 olarak hesapland1 ve PUKİ, BDÖ, BHYKÖ puanları ile arasında anlamlı ilişki olduğu belirlendi $(p<0,05)$. Ayrıca üç ölçek arasında da anlamlı pozitif korelasyon olduğu görüldü $(p<0,05)$.

\section{Tartışma ve Sonuç}

Behçet hastalarının uyku kalitesi ve depresyon düzeyleri ve etkileyen faktörleri belirlemek amaciyla yapt1ğımız çalışmada, Behçet hastalarının uyku kalitesinin kötü düzeyde olduğu ve depresyon puanının düşük olduğu belirlendi. Genital ülseri olan hastaların uyku kalitesinin daha kötü olduğu saptandı $(p<0,05)$. Diğer tanımlayıcı özellikler açısından PUKİ, BDÖ, BHYKÖ puanları arasında anlamlı bir fark bulunmadı $(\mathrm{p}>0.05)$. Hastalık aktivite skoru yükseldikçe, PUKİ, BDÖ, BHYKÖ puanlarının anlamlı olarak yükseldiği belirlendi $(\mathrm{p}<0,05)$. Ayrıca PUKİ, BDÖ, BHYKÖ arasında da anlamlı pozitif korelasyon olduğu görüldü $(p<0,05)$. BH, 1937 yılında Hulusi Behçet tarafindan tanımlanmış olup, ön planda oral aftlar, genital aftlar, oküler hastalık, deri lezyonları, gastrointestinal tutulum, nörolojik hastalık veya artrit dahil olmak üzere çeşitli sistemik belirtiler ile karakterize bir klinik hastalıktır ${ }^{32}$ Ülkemizde yapılan bir çalışmada, 184 Behçet hastasının hastalık başlangıç yaş ortalaması $20,59 \pm 4,55$ yıl 


\section{Araz, ark.}

saptanmıştır. Soylu ve ark. (2012) yaptığı çalışmada ise; hastalık başlangıç yaşı 27,6 yıl olduğu belirlenirken, bu ortalama Brezilya'da 27.37, Yunanistan'da 31.6 ve Kore'de 33,1 olarak saptanmıştır ${ }^{34}$. Çalışmamızda hastaların yaş ortalaması $37,38 \pm 8,33$ yıl ve hastalık başlangıç yaş ortalamasının ise $29,84 \pm 3,61$ olduğu saptandı. Çalışmamızda bulunan bu sonuçların literatür ile uyumlu olduğu belirlendi.

Karabacak ve ark (2014) tarafından yapılan çalışmada, oral aft tüm hastalarda saptanırken, paterji pozitifliği $\% 57,3$, genital ülser $\% 86,8$, paterji pozitifliği $\% 57,3$, göz tutulumu $\% 52,7$, vasküler tutulum $\% 22,5$, eklem tutulumu \%18,1, nörolojik tutulum \%7,11, gastrointestinal tutulum $\% 0,5$ olarak bulunmuştur ${ }^{35}$. Literatürde oral aft tutulumunun yüksek oranlarda olduğu gözlenirken, yapılan bir çalışmada paterji pozitifliğinin $\% 8$ olduğu saptanmıştır ${ }^{36,37}$. Çalışmamızda paterji pozitifliği literatürle benzer rak \%47,7 olarak saptand1.

Yapılan çalışmalarda, oküler tutulum \%50 civarında saptanırken $^{38}$, vasküler tutulum $\% 1,8-57,1$, eklem tutulumu \%16-93 $(39,40)$, nörolojik tutulum $\% 5-7^{41}$, gastrointestinal tutulum $\% 1,1-60^{33,42-43}$ oranlarında olduğu belirlenmiştir. Çalışmamızda ise; göz tutulumu $\% 45,5$, eklem tutulumu $\% 40,9$, nörolojik tutulum $\% 27,3$, gastrointestinal tutulum $\% 9,1$, vasküler tutulum \%45,2 olarak saptand. Literatürdeki benzerlik ve farklılıkların etnik köken ve sosyoekonomik farklılıklardan kaynaklanabileceği düşünülmektedir.

$\mathrm{BH}$ tekrarlayan iyileşme ve atak dönemleri ile beraber progresyon göstermekle birlikte kalıcı hasarlar oluşturabilmektedir. Özellikle hayati organ tutulumu sonrası fiziksel özürlülükler gelişebilmekte, yaşam kalitesinde belirgin etkilenim olabilmektedir. Kronik süreçle beraber kişinin bedensel ve ruhsal sağlığında bozulmalar da görülebilmektedir ${ }^{18,44}$. BH'le beraber görülen psikiyatrik problemler arasında depresyon, anksiyete psikosomatik belirtiler yer almaktadır. Bu belirtilerin hastalık sonrasında $\% 86$ gibi yüksek oranlarda görülmesine rağmen, altta yatan sebebin tam olarak açıklanamadığı bilinmektedir. Ülkemizde yapılan bir çalışmada, etyopatogenezin hastalıkta görülen progresyon, fiziksel bozulmalar ve medikal tedavi amaciyla kullanılan steroidler ile ilişkili olabileceği ileri sürülmüştür ${ }^{44}$. Ülkemizde yapılan başka bir çalışmada, 34 Behçet hastası 43 sağlıklı birey ile karşılaştırıldığında; hastalık grubunda anksiyete ve depresyon puanlarının daha yüksek olduğu saptanmıştır. Literatürde hasta grubu ile sağlıklı kişilerin kıyaslandığı birçok çalışma olduğu görülmektedir. Bu çalıșmaların sonuçları, Behçet hastalarının hastalık sürecinde psikolojilerinin olumsuz etkilendiğini ve hasta gruplarında anksiyete ve depresyon puanlarının yüksek olduğunu göstermektedir ${ }^{16,18,45}$. Bu çalışmaların aksine ülkemizde yapılan bir çalışmada ise; hastalık grubu ve sağlıklı grup arasında farklılık olmadığ 1 belirlenmiştir ${ }^{46}$. Cinsiyet ile anksiyete ve depresyon arasında ilişkinin incelendiği çalışmalarda, anksiyete düzeyinin kadın Behçet hastalarında yüksek olduğu saptanırken, depresyon puanları arasında fark olmadığı gözlenmiş$\operatorname{tir}^{16,18,45}$. Çalışmamızda, anksiyete bir değişken olarak incelenmemiş olmakla birlikte, depresyon puanının kadın hastalarda ${ }^{31,5}$ erkek hastalardan ${ }^{14,5}$ daha yüksek olduğu belirlendi. Ancak kadın hasta sayısı çok az olduğundan aradaki bu farkın anlamlı bulunmadığı görüldü.

Behçet hastalarında olumsuz etkilenen diğer bir günlük yaşam aktivitesi uyku kalitesidir. Romatolojik birçok hastalıkta uyku kalitesinin incelendiği çalışmalar mevcuttur. Ülkemizde yapılan bir çalışmada, PUKİ ortalaması Behçet hastalarında $6,4 \pm 4,4$ sağlıklı kişilerde $3,1 \pm 1,4$ olarak saptanmıştı ${ }^{47}$. Başka bir çalışma-

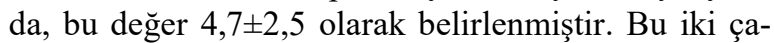
ış̧mada PUKİ ortalamalarındaki farkın, hastalık aktivitesinden kaynaklanabileceği düşünülmektedir ${ }^{48}$.

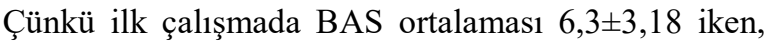
diğer çalışmada hastalık aktivite skor ortalaması 4,4 $\pm 2,4$ olarak bulunmuştur. Hastalık aktivitesindeki artışın hem uyku kalitesinde bozulmaya hem de depresif belirtilerde artışa sebep olduğu çeşitli çalışmalarda gösterilmiştir ${ }^{47,48}$. Taşçılar ve ark. (2012) tarafindan yapılan çalışmada, özellikle genital ülser ve artrit semptomlarının uykuya dalmayı zorlaştırdığı, her iki grup ile rem uykusu latansında azalma arasında ilişki olduğu ortaya konmuştur ${ }^{21}$. Çalışmamızda, PUKİ ortanca değerinin 6.5 olduğu, özellikle hastalık aktivasyonu ve genital ülser varlığında uyku kalitesinde bozulmalar olduğunun belirlenmesi literatür ile benzerdir.

Behçet hastalarında özellikle uyku kalitesinde bozulmalar ve psikojenik etkilenimin yanı sıra yaşam kalitesi de olumsuz etkilenebilmektedir. Yaşam kalitesini değerlendirmek amacıyla çeşitli ölçekler geliştirilmiştir. Kısa form-36 kullanılarak yapılan bir çalışmada, hasta grubunda kontrol grubuna göre tüm alanlarda daha düşük puanlar saptanmıștır. Hasta grubunda, hastalar aktif ve remisyon olarak iki grupta değerlendirilmiş olup, aktif gruptaki hastalarda canlılık, mental ve fiziksel sağlık alanlarındaki puanlar daha düşük saptanmıştır ${ }^{47}$. Ülkemizde yapılan başka bir çalışmada ise; 33 Behçet hastası 33 sağlıklı birey ile karşılaştırılmıs, Kısa Form-36'nın fiziksel fonksiyon ve canlılık dışındaki diğer alt boyutlarında Behçet hastalarında daha düşük puanlar saptanmıştır. Ancak aynı çalışmada, remisyon ve aktif grup hastalar arasinda anlamlı fark saptanmamışıır ${ }^{18}$. Dermatolojik yaşam kalitesi ölçeğinin kullanıldığı bașka bir çalışmada, Behçet hastaları psöriyazis hastaları ile karşılaştııılmış, puan ortalamaları psöriyazis grubunda yüksek olmasina rağmen istatistiksel fark saptanmamıştır. Dermatolojik yaşam kalitesi ölçeği alt boyutlarından bilişşsel işlev ve duygusal yaşam alt alanlarında psöriyazis hastalarının istatistiksel olarak anlamlı derecede yüksek puanlar aldıkları saptanmıştır ${ }^{49}$. Çalışmamızda, yaşam 


\section{Behçet Hastalarının Uyku Kalitesi}

kalitesini değerlendirmek amacıyla Behçet Hastalığ Yaşam Kalitesi Ölçeği kullanılmış olup, ortanca değerin 11,5 olduğu ve hastalık aktivasyonunun yaşam kalitesini olumsuz etkilediği belirlendi.

Sonuç olarak, tüm organ ve sistemlerin etkilendiği Behçet hastalarında uyku kalitesinin kötü olduğu ve uyku kalitesi ile depresyon ve yaşam kalitesi arasında ilişki olduğu belirlendi. Genital ülser varlığının uyku kalitesini olumsuz etkileyen önemli bir faktör olarak öne çıktığı görüldü. BH gibi birçok semptom ve belirtilerin görüldüğü kronik hastalıklarda, hastaların bütüncül olarak ele alınmasının önemli olduğu düşünülmektedir. Hastalık aktivitesinin kontrol altında tutulabilmesi amaciyla, erken tanı ve tedavinin ve remisyona erken ulaşmanın önemli olduğu düşünülmektedir. Bununla birlikte, hastaların medikal tedavi yanında biyopsikososyal olarak tüm açılardan değerlendirilmeli ve gerekli durumlarda psikiyatrik destek almak üzere yönlendirilmesi sağlanmalıdır.

Etik Kurul Onay Bilgisi:

Onaylayan Kurul: Uludağ Üniversitesi Tıp Fakültesi Klinik Araştırmalar Etik Kurulu.

Onay Tarihi: 07.05.2019

Karar No: 2019-8/42

\section{Kaynaklar}

1. Evereklioglu C. Current concepts in the etiology and treatment of Behcet disease. Surv Ophthalmol 2005;50:297-350.

2. Onder M, Gurer MA. The multiple faces of Behcet's disease and its aetiological factors. J Eur Acad Dermatol Venereol 2001;15:126-136.

3. Ghate JV, Jorizzo JL. Behcet's disease and complex aphthosis. J Am Acad Dermatol 1999;40:1-18.

4. Pay S. Behçet hastalığı: etiyoloji ve patogenez. T Klin J Int Med Sci 2005;1:10-18.

5. Arca E, Gür AR. Behçet Hastalığı. T Klin J Med Sci 2003;23:261-268.

6. Doğanavşargil E, Keser G. Behçet hastalığı. T Klin J Int Med Sci 2005;1:80-91.

7. Boyvat A. Behçet hastalığının etiyopatogenezi. T Klin J Dermatol 2004;1415-1421.

8. Yurdakul S, Hamuryudan V, Yazici H. Behçet syndrome. Curr Opin Rheumatol. 2004;16(1):38-42.

9. Hegab S, Al-Mutawa S. Immunopathogenesis of Behçet's disease. Clin Immunol 2000;96: 174-86.

10. Yurdakul S, Tüzün Y, Mat MC, Özyazgan Y, Yazıcı H. Behçet sendromu. Dermatoloji Ed. Tüzün Y, Kotođyan A, Aydemir EH, Baransü O. Istanbul 1994;393-8.

11. Gül A. Behçet hastalığının immünolojisi. Aktüel Tıp Dergisi 1997;2: 76-8.

12. Akpolat T, Koc Y, Yeniay I, et al. Familial Behçet's disease Eur J Med 1992;1: 391-5

13. Marshall SE. Behçet's disease. Best Pract Res Clin Rheumatol. 2004; 18:291-311

14. Stojanovich L. Stress and autoimmunity. Autoimmun Rev, 2010, 9: 271-276
15. Calıkoglu E, Onder M, Cosar B, Candansayar S. Depression, anxiety levels and general psychological profile in Behçet's disease. Dermatology, 2001, 203.3: 238-240.

16. Karlıdağ R, Unal S, Evereklioglu C, Sipahi B, Er H, Yologlu S. Stressful life events, anxiety, depression and coping mechanisms in patients with Behçet's disease. Journal of the European Academy of Dermatology and Venereology, 2003, 17.6: $670-675$.

17. Sharma P, Avasthi A, Chakrabarti S. Depression among hospitalised medically ill patients: a two stage screening study. J Affect Disord. 2002, 70:205-209

18. Uguz F, Dursun R, Kaya N, Cilli AS. Behçet hastalarında ruhsal belirtiler ve yaşam kalitesi. Anadolu Psikiyatri Dergisi 2006;7:133-139

19. Alpsoy E. Behçet hastalığının deri ve mukoza belirtileri. TÜRKDERM 2003;37:92-99.

20. Köse O, Gür AR. Dermatolojide yapam kalitesi ve ölçümü. T Klin Dermatol 2000;10:270-274

21. Tascilar NF, Tekin NS, Ankarali H, et al. Sleep disorders in Behçet's disease, and their relationship with fatigue and quality of life. J Sleep Res. 2012;21:281-288.

22. Melikoglu MA, Melikoglu M. The relationship between disease activity and depression in patients with Behcet disease and rheumatoid arthritis. Rheumatol Int 2010; 30:941-94.

23. Buysse DJ, Reynolds CF 3rd, Monk TH, Berman SR, Kupfer DJ. The Pittsburgh Sleep Ouality Index: a new instrument for psychiatric practice and research. Psychiatry Res 1989;28(2):193-213;

24. Ağargün MY, Kara H, Anlar Ö. Pittsburgh Uyku Kalitesi İndeksi'nin Geçerliliği ve Güvenilirliği. Türk Psikiyatri Dergisi 1996;7(2):107-115.

25. Pehlivan S, Karadakovan A, Pehlivan Y, Onat AM. Sleep quality and factors affecting sleep in elderly patientswith rheumatoid arthritis in Turkey. Turk J Med Sci. 2016;46(4):1114-21. doi: 10.3906/sag-1506-82.

26. Beck AT, Ward C, Mendelson M. Beck depression inventory (BDI). Arch Gen Psychiatry, 1961;4(6):561-571.

27. Hisli N. Beck Depresyon Envanterinin üniversite öğrencileri için geçerliği, güvenirliği. Psikoloji dergisi, 1989;7(23):3-13.

28. Gilworth $\mathrm{G}$ et al. Development of the BD-QoL: A quality of life measure specific to Behcet's disease. J Rheumatol 2004;31(5):931-937.

29. Erdoğan Z, Pinar R. Evaluation of quality of life in Behçet's disease. Eur J Intern Med 2009;20(suppl 1):s156-7.

30. Tuğrul Ayanoğlu B, Gürler A, Erdoğan FG, Gündüz Ö, Alhan A. Behçet ve rekürren aftöz stomatit hastalarında yaşam kalitesi. Turkderm - Arch Turk Dermatol Venerology 2015;49:27684. doi: 10.4274 /turkderm.00868.

31. Bhakta BB, Brennan P, James TE, Chamberlain MA, Noble BA, Silman AJ. Behcet's disease: evaluation of a new instrument to measure clinical activity. Rheumatology, 1999;38(8):728-733.

32. Hamuryudan V, Fresko I, Direskeneli H, et al. Evaluation of the Turkish translation of a disease activity form for Behçet's syndrome. Rheumatology, 1999;38(8):734-736.

33. Shimizu T, Ehrlich GE, Inaba G, Hayashi K. "Behçet disease (Behçet syndrome)." Seminars in arthritis and rheumatism. 1979;8(4):223-60

34. Soylu M, Şekeroğlu HT, Erdem E, Demircan N. Behçet's Disease: The Clinical and Demographic Characteristics of 406 Patients. Turk J Rheumatol 2012;27:115-20.

35. Karabacak E, Aydın E, Doğan B, et al. "Behçet hastalığı: 182 hastanın klinik ve demografik özellikleri." Archives of the Turkish Dermatology \& Venerology/Turkderm 2014;48(3):121-6. 


\section{Araz, ark.}

36. Tursen U, Gurler A, Boyvat A. Evaluation of clinical findings according to sex in 2313 Turkish patients with Behçet's disease. Int J Dermatol 2003;42:346- 51.

37. Dogan B, Taskapan O, Harmanyeri Y. Prevalance of pathergy test positivity in Behçet's disease in Turkey. J Eur Acad Dermatol Venereol 2003;17:228-9.

38. Özyazgan Y. Behçet Hastalığında Göz Tutulumu. Turkderm 2009;43 Özel Sayı:48-53

39. Bang D, Lee J, Lee E, et al. Epidemiological and clinical survey of Behcet's disease in Korea: the first multicenter study. J Korean Med Sci 2001;16:615-8.

40. El Menyawi MM, Raslan HM, Edrees A. Clinical features of Behcet's disease in Egypt. Rheumatol Int 2009;29:641-6.

41. Akman-Demir G. Behçet Hastalığında Nörolojik Tutulum. Turkderm 2009;43 Özel Sayı:61-4.

42. Oshima Y, Shimizu T, Yokohari R, et al. Clinical studies on Behçet's syndrome. Ann Rheunz Dis 1963;22:36-45.

43. Yurdakul S, Tuzuner N, Yurdakul I, et al. Gastrointestinal involvement in Behçet's syndrome: a controlled study. Ann Rheum Dis 1996;55:208-10.
44. Taner E, Burhanoğlu S, Coşar B, Önder M. Behçet hastalığı olan hastalarda anksiyete ve depresyonun psoriyazis hastalarıyla karşılaştırılması. Türkiye'de psikiyatri 2006;8:27-29.

45. Havlucu DY, Inanır I, Aydemir Ö. Behçetli hastalarda yaşam kalitesi, anksiyet,depresyon ve hastalık hakkındaki bilgiler. Anatol J Clin İnvestig 2011:5;82-88.

46. Eren I, Şahin M, Cüre E, Çivi-İnanlı I, Tunç ȘE. Psychiatric symptoms and quality of life in patients with Behcet's disease. 2006;13:169-174.

47. Koca I, Savas, E., Ozturk, Z. et al. The relationship between disease activity and depression and sleep quality in Behçet's disease patients. Clinical rheumatology, 2015; 34(7): 12591263.

48. Herdi, O., \& Cankorur, V. Ş. Behçet Hastalığı Olanlarda Uyku Kalitesinin ve Uyku Kalitesi ile Hastalık Aktivitesi Arasındaki İlişkinin Değerlendirilmesi. Kriz Dergisi, 26(3), 1-1.

49. Yılmaz Y. Behçet hastalarındaki yaşam kalitesi, cinsel sorunlar, anksiyete ve depresyon düzeylerinin psoriyazis hastaları ve sağlıklı gönüllüler ile karşılaştırılması. Dokuz Eylül Üniversitesi Tıp Fakültesi, 2011. 